\title{
Investigation of The Influence of Halogens, Cycloalkanes, Carbonyls and the Hydroxyl Groups on The Reactivity of 1, 3-Butadienes With Imine Dienophile: Insight From DFT, MEDT, and QTAIM
}

Fredrick Asogwa ( $\nabla$ fredrick.asogwa@gmail.com )

University of Calabar

Hitler Louis

University of Calabar

Dollars I. Kenthurky

University of Calabar

Obieze C. Enudi

University of Calabar

\section{Research Article}

Keywords: DFT calculations, NBO, HOMO-LUMO, MEDT, Diels-Alder reaction

Posted Date: October 19th, 2021

DOI: https://doi.org/10.21203/rs.3.rs-911801/v1

License: (9) (i) This work is licensed under a Creative Commons Attribution 4.0 International License.

Read Full License 


\title{
Investigation of the Influence of Halogens, Cycloalkanes, Carbonyls and the Hydroxyl Groups on the Reactivity of 1, 3-Butadienes with Imine Dienophile: Insight from DFT, MEDT, and QTAIM
}

\author{
Fredrick C. Asogwa*, Hitler Louis*, Dollars I. Kenthurky, and Obieze C. Enudi \\ Computational and Bio-Simulation Research Group, Department of Pure and Applied Chemistry, \\ Faculty of Physical Sciences, University of Calabar, Calabar, Nigeria \\ Corresponding author's email: fredrick.asogwa@gmail.com and louismuzong@gmail.com

\begin{abstract}
The presence of nitrogen atom either on the diene or the dienophile structure gives rise to aza or imino-Diels-Alder reactions (DARs). Among hetero-DARs, imino-dienophiles yields numerous functionalized compounds with numerous biological activities including but not limited to antifungal, antibacterial and enzymatic properties. Density functional theory (DFT) using the B3LYP functional at the 6-31+G $(\mathrm{d}, \mathrm{p})$ basis set along with topological studies (QTAIM) were used for the investigation of 10 different (SD1-SD10) DARs which differ in the nature of substituents groups attached to the diene molecule. The study indicates higher electron density and stronger interaction for substituted dienes with the cycloalkanes, furan, carbonyl, and $-\mathrm{OH}$ groups. It was observed in the HOMO-LUMO energy differences that the bulky groups; SD3, SD4, and SD6 had destabilization energy of -7.86 and $0.09,-7.88$ and 0.10 and -7.50 and -0.014 $\mathrm{eV}$ respectively in their HOMO and LUMO levels while the halogen substituted dienes SD1, SD2, and SD5 had -8.20 and $-0.32,-8.31$ and -0.34 and -8.19 and $-0.20 \mathrm{eV}$ respectively. The study showed that synthesis of hetero-nuclear aza-cyclohexene is achieved faster with furan substituent of energy gap $7.534 \mathrm{eV}$ and molecular hardness of 3.677 compared to 7.799 (SD7) $8.100 \mathrm{eV}$ (SD8) and 3.899 (SD7) - 4.050 (SD8) respectively scored by other substituents noting that smaller energy gap leads to higher reactivity. $\mathrm{HCOCH}_{3}$ (SD8) retarded the rate of the reaction by about 58\% (unspontaneous) following the calculated Gibb's free energy of activation while SD6 in the ELF analysis showed complete covalent character against other cycloalkanes that showed dual characteristics of a double and single bond between $\mathrm{N}-\mathrm{C}$ at their transition states.
\end{abstract}

Key words: DFT calculations, NBO, HOMO-LUMO, MEDT, Diels-Alder reaction. 


\subsection{Introduction}

The original version of the Diels-Alder reaction (DAR) involves 1, 3-dienes and an alkene dienophile as reactants. However, progressive chemistry research in all areas; synthetic-organic chemistry, polymer, material science, and natural product has improved the works of Otto Diels and Kurt Alder allowing hetero-dienes and hetero-dienophiles to be applicable following the same $(4+2)$ cycloaddition reaction mechanism [1]. Notable researchers have in the past employed DAR in various areas of chemistry and material science [1,2-3]. This is sequel to numerous available dienophiles. Yang et al reported that following this reaction mechanism, trans-cyclooctenes are employed for high reaction rate while cyclopropenes are used for metabolic reactions [4-5]. Structural modification of trans-cyclooctene using carbamate promotes drug design [6]. Boger et al [7] reported the synthesis of streptonigrone and Weinreb and group reported phyllanthine while Danishefsky and Jacobsen and co-workers respectively reported the successful synthesis of ipalbidine and (+) - reserpine [9]. Song and co-workers [1] evaluated the factors controlling the Diels-Alder reactivity of hetero- 1, 3-butadienes with ethylene. They found that unsubstituted 1, 3-butadiene reacts with ethylene moderately with an activation energy of $15.2 \mathrm{Kcal} / \mathrm{mol}$. However, substitution of carbon atoms greatly influences the reactivity of these dienes. According to their report, if one or two terminal carbon atoms are substituted, the rate of the reaction is reduced remarkably.

Hetero-DARs are taking the lead in the synthetic processes for both natural and other heterocyclic industrial products [10]. The presence of nitrogen atom either on the diene or the dienophile structure gives rise to aza or imino-DAR. Again, among hetero-DARs, iminodienophiles yields numerous functionalized aza-compounds with effective control over stereo-, regio- and enantio-selectivity [11]. The imines are important because of their numerous biological activities. They are incorporated naturally or artificially in many chemical structures and have shown antifungal, antibacterial and enzymatic properties [12-16]. In material science, they are employed as monomers for synthesis of polymers, reaction intermediates, corrosion inhibitors and cataysts [17-23].

DARs generally follow either a concerted or step wise $\pi 4 s+2 s \pi$ cycloaddition pathways. It is either Homo diene- controlled or the neutral reaction and the inverse electron demand Lumo dienecontrolled reaction. The HOMO-LUMO energy difference between the diene and the dienophile determines the type and rate of the cycloaddition process. Previous report adopted the molecular orbital calculations at $6-31 \mathrm{G}$ and MP2/6-31G* basis sets level of theory to show that the transition state of formaldimine with butadiene is $4.3-5.3 \mathrm{Kcal} / \mathrm{mol}$ more stable when the nitrogen lone pair is exo than when it is in the endo orientation [24]. They suggested that the reason could be due to repulsion between the lone pair and the 1,3-butadiene pi electrons. Hetero-DARs are indispensable tools employed in both organic and natural product chemistry for regio- and stereo-selective synthesis of heterocyclic compounds [24-25]. Reaction yield is enhanced when an electron-rich group is attached onto the diene or the electron-poor substituent is on the dienophile [25]. Recently, Safa et al [25] investigated the regio-selectivity in heteroDARs of styrenes with and without substituents with 2-aza-1, 3-butadiene. Their calculations using the Gaussian 09 software at the B3LYP/6-311++G** level of theory show that formation 
of 4-regio-isomers were favoured for reaction involving electron-releasing substituents while strong electron-withdrawing groups lead to formation of 5-regio-isomers as shown in Figure 1 (a-d), where $\mathrm{X}$ represents $\mathrm{H}, \mathrm{F}, \mathrm{CH}_{3}, \mathrm{OH}, \mathrm{NH}_{2}, \mathrm{CN}$, and $\mathrm{NO}_{2}$. Experimental result according to $\mathrm{Yu}$ and Kuiling [26] showed that a high yield of $>99 \%$ was obtained by aza-DAR of Danishefsky diene with imine in methanol without any acid catalyst. They also evaluated the effect of solvent and confirmed that the reaction proceeded more in polar solvents than in non-polar solvents like toluene, diethyl ether, chloroform and dichloromethane which yielded $<5 \%$ of the product [26].

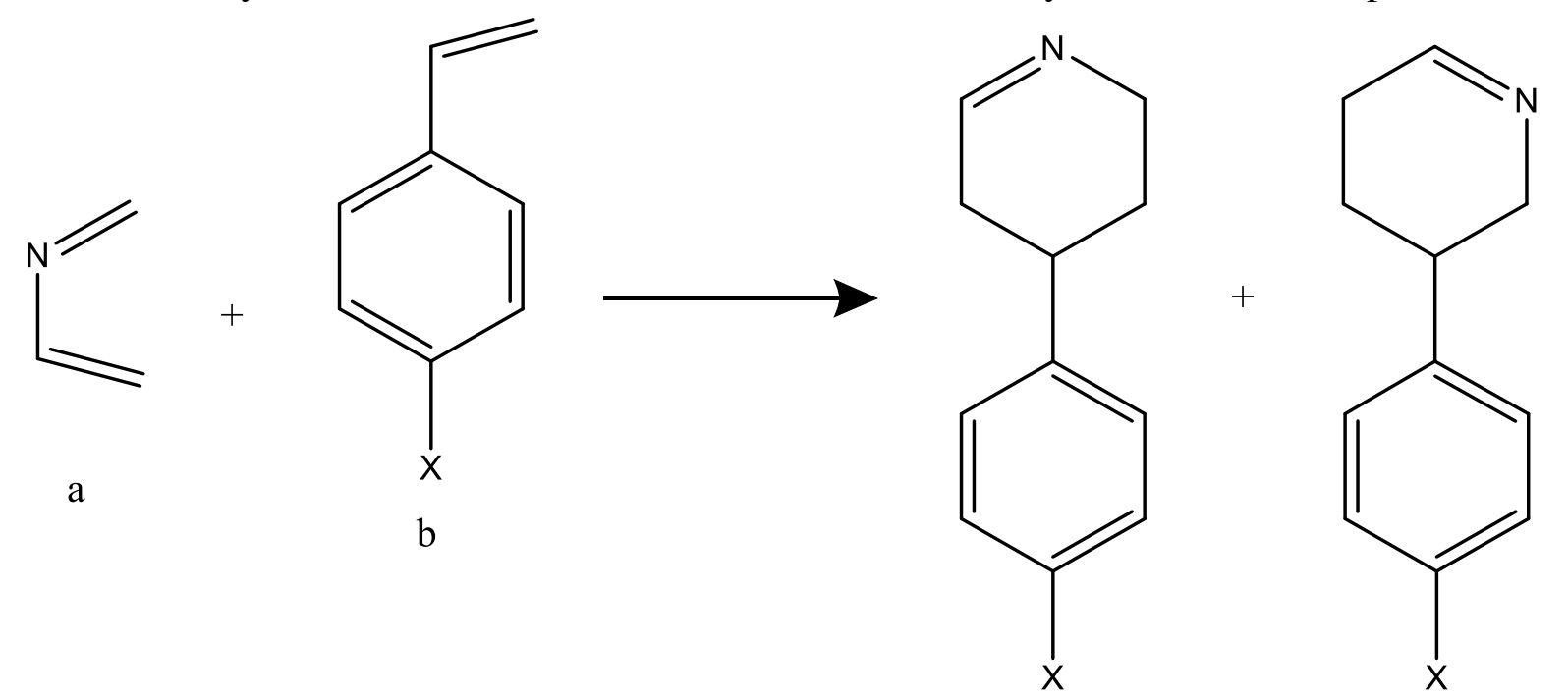

Figure 1

$\mathrm{d}$

where $\mathrm{X}=\mathrm{H}, \mathrm{F}, \mathrm{CH}_{3}, \mathrm{OH}, \mathrm{NH}_{2}, \mathrm{CN}$ and $\mathrm{NO}_{2}$

Although, the influence of substituents on 1,3-butadiene is available in literature, to the best of our knowledge, there is paucity or no report on the reaction characteristics of hetero-DARs of 1 , 3-butadiene substituted with these groups and imino-dienophile. Hence, we aimed to carry out a first principle density functional theory (DFT) comparative study of the influence of halogens, cycloalkanes, carbonyls and hydroxyl group substituents on the reaction characteristics of 1, 3butadiene represented as SD1-SD10 (see Fig. 2) with aza-ethylene dienophile in the gas phase. The DFT study of the DARs is evaluated through the frontier molecular orbital (FMO) analysis, natural bond orbital (NBO) analysis, global reactivity descriptors (GRD), quantum theory of atoms-in-molecules (QTAIM), molecular electron density theory (MEDT), global electron density transfer (GEDT), and the thermodynamics of the studied reactions.

\subsection{Computational Methods}

Density Functional Theory (DFT) calculations were performed using the Gaussian09 computational software [27] in combination with GaussView 6.0.16 [28]. The geometries of reactants, transition states, and the product structures were optimized by the B3LYP functional [29] at the $6-31+\mathrm{G}(\mathrm{d}, \mathrm{p})$ basis set without any symmetry constrains. The reactant and product had real frequencies while the transition state (Ts) had single imaginary frequency in the 
diagonalized Hessian matrix. Intrinsic reaction co-ordinate (IRC) calculations were carried out to confirm that the local transition states are connected to the corresponding minimum stationary points. The quantum theory of atoms-in-molecule (QTAIM) analysis was employed to estimate the effect of hydrogen bonding interaction effective at the Ts using the Multiwfn program [28]. The frontier molecular orbital (FMO), energy gap, and quantum chemical descriptors were as well calculated as previously described [29]. The natural bond order (NBO) and GEDT from NBO analysis of the Ts were computed using the Multiwfn program so as to determine how fast the reaction proceeded or delayed and the molecular electron density theory (MEDT) [31] was employed to elucidate the electron localization function [30].

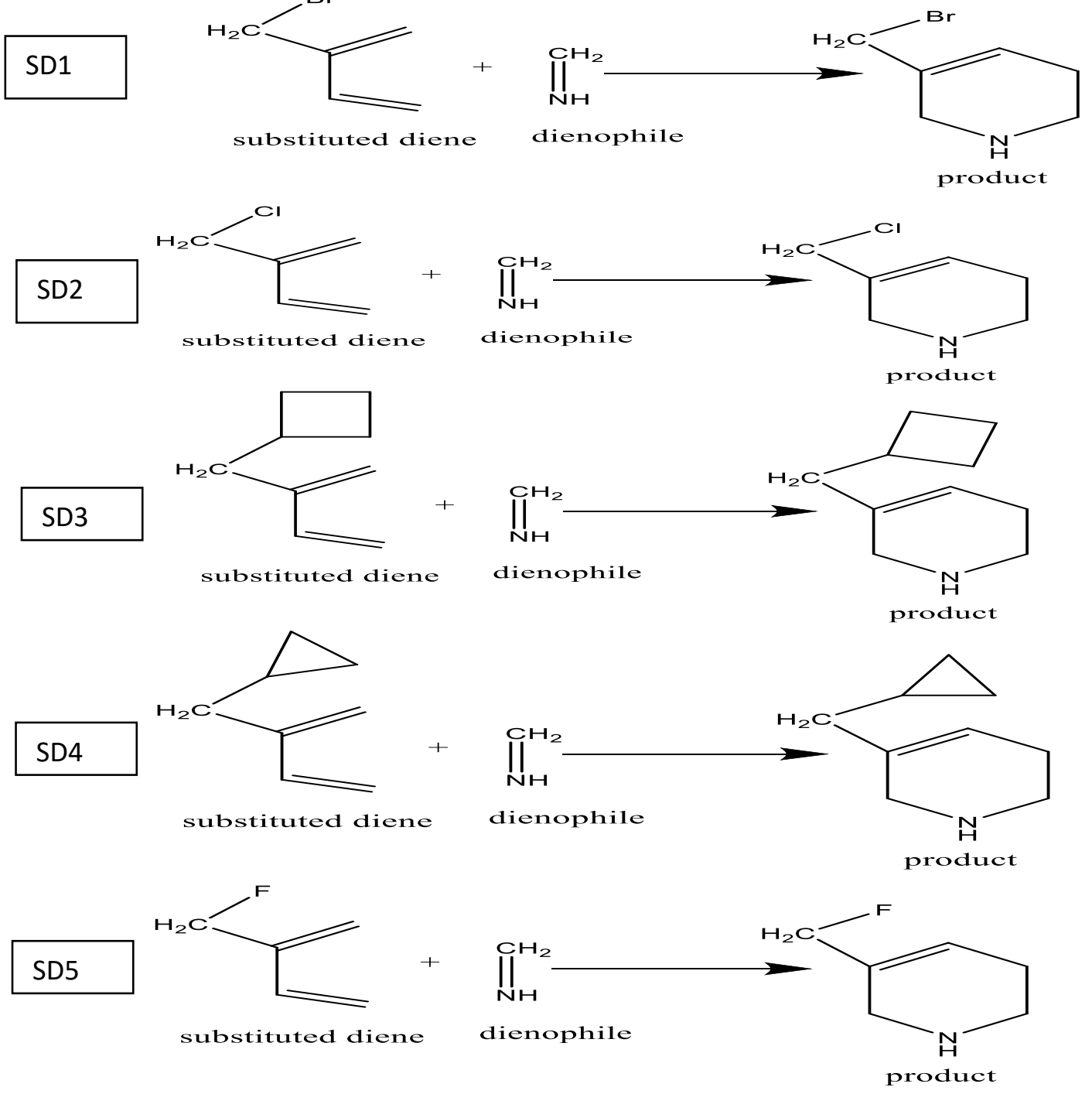




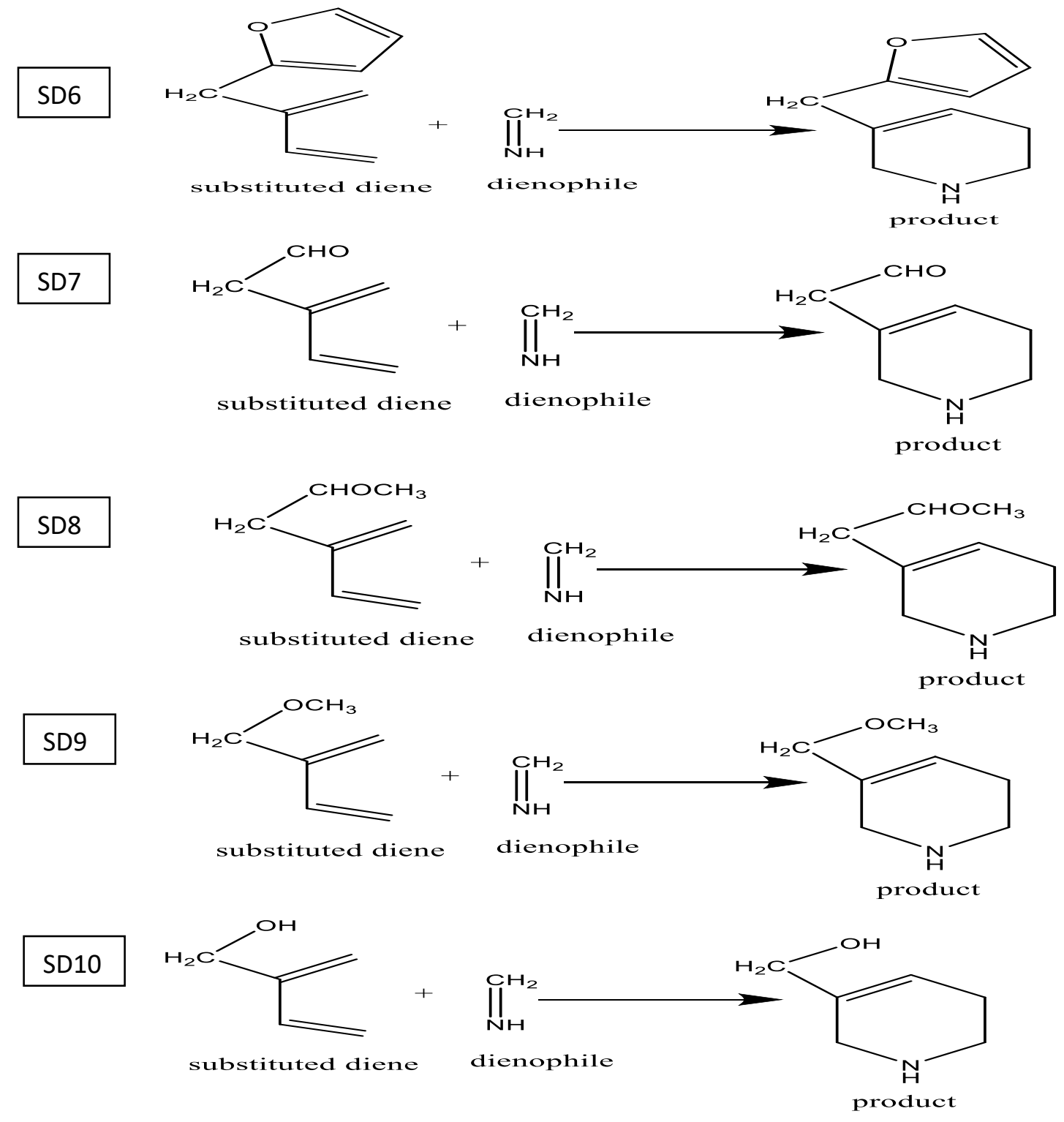

Fig.2: Schematic diagram of $\mathrm{SD}_{1}-\mathrm{SD}_{10}$ reactions

\subsection{Results and Discussion}

\subsection{The Quantum Theory of Atoms in Molecule (QTAIM)}

QTAIM analysis is proven to be very useful in determining the nature of atomic interactions in chemical systems and ionic clusters according to Arumugam et al [32]. It explains the noncovalent and hydrogen bond interactions between $\mathrm{H}$-bond donor and acceptor atoms using the data generated from the $(3,-1)$ bond critical points (BCPs). Electron density rho $(\rho)$ measures the strength of the interaction between atoms in molecules. Experimental research has shown that covalent bonding interactions have $\rho$ values above 0.20 a.u while non-covalent interactions have 
$\rho$ values less than 0.10 a.u. Table S7(c) of the supporting information shows the electron density and laplacian values from the $(3,-1)$ computed BCPs. The $\rho$ values for incipient $\mathrm{C}-\mathrm{C}$ bond is indicative of the strong bond formations between the dienes and the dienophile. The order of strength of atomic interaction is SD4>SD6>SD3>SD9>SD10>SD7>SD1 $>$ SD5 $>$ SD2 $>$ SD8 and the range of electron density values were $0.297(\mathrm{C} 5-\mathrm{C} 1)$ to $4.230(\mathrm{C} 3-\mathrm{C} 4), 0.297(\mathrm{C} 5-\mathrm{C} 1)$ to $4.226(\mathrm{C} 3-\mathrm{C} 4), 0.248(\mathrm{C} 5-\mathrm{C} 1)$ to $4.218(\mathrm{C} 3-\mathrm{C} 4), 0.251(\mathrm{C} 5-\mathrm{C} 1)$ to 4.149 (C3-C4), 0.297 $(\mathrm{C} 5-\mathrm{C} 1)$ to $3.928(\mathrm{C} 3-\mathrm{C} 4), 0.296(\mathrm{C} 5-\mathrm{C} 1)$ to $3.886(\mathrm{C} 3-\mathrm{C} 4), 0.297(\mathrm{C} 5-\mathrm{C} 1)$ to 3.802 $(\mathrm{C} 3-\mathrm{C} 4), 0.296(\mathrm{C} 5-\mathrm{C} 1)$ to $3.760(\mathrm{C} 3-\mathrm{C} 4), 0.155(\mathrm{C} 1-\mathrm{C} 2)$ to $3.646(\mathrm{C} 3-\mathrm{C} 4)$, and 0.276 $(\mathrm{C} 5-\mathrm{C} 1)$ to $0.334(\mathrm{C} 4-\mathrm{C} 5)$. Critical study of the data shows the asynchronous nature of the transition states (Ts) between the dienes (SD1-SD10) and the dienophile. High values of electron density obtained for the reaction was further supported by the molecular graphs provided in Figure 3 depicting the nature of orbitals at their transition states. It is interesting to note also that the QTAIM result was in line with the result from the thermodynamic studies where the computed reaction energies and the asynchronous nature of the transition states were found to correlate. The present study indicates higher electron density and hence, stronger interaction for substituted dienes with the cycloalkanes, furan, carbonyl, and - $\mathrm{OH}$ groups scoring higher than the halogen substituted dienes. This observation is probably due to increased H-bonding interaction between the $\mathrm{H}$-bond donor diene and the acceptor dienophile and the strong $\mathrm{O}-\mathrm{H}$ interactions in SD6, SD4, SD3, SD9, and SD10 which are substituted dienes with bulky groups attached to them. It is important to note that SD8 had the least electron density value which resulted in minimal interaction especially between $\mathrm{C} 3$ and $\mathrm{C} 4$ atoms.

\subsection{Natural Bond Orbital Analysis}

The natural bond orbital analysis was employed to explain the stabilizing interactions between the donor and the acceptor species. The second-order perturbation energy helps to pinpoint electronic interactions leading to increased rate of reaction in DARs. The result of the NBO analysis is shown in Table S1 of the supporting information (SI). The common donor-acceptor interactions for all the dienes and dienophile were $\pi \rightarrow \pi^{*}$ and $\pi^{*} \rightarrow \pi^{*}$ interactions except SD8 that exhibited $\sigma \rightarrow \sigma^{*}$ and $\sigma^{*} \rightarrow \pi^{*}$ in addition to $\pi \rightarrow \pi^{*}$ interactions. Their stabilizing energy ranged from 14.99 (SD8) to $250.34 \mathrm{Kcal} / \mathrm{mol}$ (SD4). These strong interactions were attributed to the asynchronous nature of the transition states and particularly SD3, SD4 and SD6 which were comparatively more because of their respective bulky cyclobutane, cyclopropane and furan substituents. The interactions were 26.80 to $250.34 \mathrm{Kcal} / \mathrm{mol}$ emanating from incipient C3-N25 and C1-C2 bond distances of 1.311 and $1.387 \AA$ respectively. Arumugam et al [32] also reported $\pi \rightarrow \pi^{*}$ interactions between substituted 1, 3-butadiene and 2-bromocyclobutenone dienophile to be in the range of 13.6 to $225.4 \mathrm{Kcal} / \mathrm{mol}$. Bulky group substituents are responsible for increased interaction aside other factors as seen from the present study. SD3, SD4 and SD6 which are bulkier had second-order perturbation energies of 15.44-72.07, 26.80-250.34 and 21.83-164.43 $\mathrm{Kcal} / \mathrm{mol}$ respectively. Again, SD7, SD9 and SD10 also had energies of interaction in the range of 22.81-77.28, 28.17-198.01 and 27.93-194.00 Kcal/mol respectively. This is evidently expected due to stabilizing interactions between the donor and the acceptor orbitals and the 
enhanced intermolecular hydrogen bonding within this group of substituted butadiene. Expectedly for the halogen substituted dienes, because they present electron-withdrawing effect, the dienes became deactivated compared to other groups under investigation. SD1, SD2 and SD5 which were dienes respectively substituted by $\mathrm{Br}, \mathrm{Cl}$ and $\mathrm{F}$ had energies of interaction in the range of 22.54-32.93, 14.75-23.68 and 24.85-41.85 Kcal/mol respectively.

\subsection{Frontier Molecular Orbital Analysis}

The calculated quantum chemical descriptors, energy gap along with the HOMO and LUMO of the studied dienes and dienophile are shown in Table 1 while the HOMO-LUMO orbital plots along with the corresponding electrostatic potential for each Ts product are presented in Fig. 3. Computer-assisted electrostatic potential map uses different colours to indicate the distribution of charges around the nuclei in molecules. Electrostatic potential is a physical property and very useful in exploring molecular reactivity. Deep red colour shows the electron-rich regions on the map indicating where negative charges are localized while dark blue colour indicates regions of electron deficiency. It corresponds to the nucleophilic positive sites. The intermediate colours like light blue is indicative of slightly electron deficient sites and yellow colour means slightly electron-rich region while green shows neutral regions. Frontier molecular orbital analysis provides information not only on the reactivity of molecules but also on the electronic structure [26]. The destabilizing energy of the HOMO and LUMO levels of the dienes are in line with our conclusions on the reactivity of the substituted butadienes. Here, it was observed that the bulky groups; SD3, SD4 and SD6 had destabilization energy of -7.86 and 0.09, -7.88 and 0.10 and 7.50 and $-0.014 \mathrm{eV}$ respectively in their HOMO and LUMO levels while the halogen substituted dienes SD1, SD2 and SD5 had -8.20 and $-0.32,-8.31$ and -0.34 and -8.19 and $-0.20 \mathrm{eV}$ respectively. The carbonyl substituted dienes SD7 (formaldehyde), SD8 (ethanal) followed the same trend with the halogens. Their destabilization energy of the HOMO and LUMO levels were -8.17 and -0.37 and -8.14 and $-0.04 \mathrm{eV}$ respectively while SD9 (methoxy group substituent) and SD10 (hydroxyl group substituent) were destabilized by -7.88 and 0.04 and -7.87 and $0.05 \mathrm{eV}$ of energy in their HOMO and LUMO levels. It is important to compare the quantum chemical descriptors values with other analyses result to ascertain the overall reactivity terms. Chemical descriptors such as hardness and softness directly affect the reactivity of molecules. Increase in hardness $(\eta)$ decreases reactivity while softness is directly related to reactivity. Chemical quantum descriptors shown in Table 1 were calculated using equations 1-8.

$$
\begin{aligned}
& \mathrm{IP}=-\mathrm{E}_{\text {HOMO }} \\
& \mathrm{EA}=-\mathrm{E}_{\text {LUMO }}
\end{aligned}
$$

Using koopman's theorem, the following electronic descriptors were computed.

$$
-\mu=1 / 2\left(\mathrm{E}_{\text {HOMO }}+\mathrm{E}_{\mathrm{LUMO}}\right)=\chi
$$


$\eta=1 / 2(I P-E A)=\frac{\mathrm{E}_{\mathrm{LUMO}}-\mathrm{E}_{\mathrm{HOMO}}}{2}$

$\omega=\frac{\mu^{2}}{2 \eta}$

$\mathrm{S}=\frac{1}{2 \eta}=\frac{1}{I P-E A}=\frac{1}{\mathrm{E}_{\mathrm{LUMO}}-\mathrm{E}_{\mathrm{HOMO}}}$

$\mathrm{W}^{+}=(\mathrm{IP}+3 \mathrm{Ea})^{2} / 16(\mathrm{IP}-\mathrm{Ea})$

$\mathrm{W}^{-}=(3 \mathrm{IP}+\mathrm{Ea})^{2} / 16(\mathrm{IP}-\mathrm{Ea})$

Among the substituted butadienes, SD6 (furan substituted diene) showed the least hardness of $3.67 \mathrm{eV}$ and others were in the range of $3.96 \mathrm{eV}$ (SD9, SD10) to $4.05 \mathrm{eV}$ (SD8).

Table 1: HOMO-LUMO and Quantum Descriptors

$\begin{array}{lccccccccccc} & \text { HOMO } & \text { LUMO } & \text { IP } & \text { EA } & \text { Eg } & \mu & \eta & w & w+ & w- & \text { X } \\ & & & & & & & & & & & \\ \text { SD1 } & -8.208 & -0.327 & 8.208 & 0.327 & 7.880 & 4.267 & 3.940 & 4.621 & 0.669 & 4.681 & -4.267 \\ \text { SD2 } & -8.318 & -0.348 & 8.318 & 0.348 & 7.970 & 4.333 & 3.985 & 4.711 & 0.687 & 4.748 & -4.333 \\ \text { SD3 } & -7.863 & 0.0985 & 7.863 & 0.098 & 7.962 & 3.882 & 3.981 & 3.786 & 0.449 & 4.405 & -3.882 \\ \text { SD4 } & -7.887 & 0.1017 & 7.887 & 0.101 & 7.988 & 3.892 & 3.994 & 3.793 & 0.449 & 4.417 & -3.892 \\ \text { SD5 } & -8.196 & -0.202 & 8.196 & 0.202 & 7.994 & 4.199 & 3.997 & 4.412 & 0.606 & 4.650 & -4.199 \\ \text { SD6 } & -7.501 & -0.146 & 7.501 & 0.146 & 7.354 & 3.823 & 3.677 & 3.976 & 0.535 & 4.247 & -3.823 \\ \text { SD7 } & -8.174 & -0.374 & 8.174 & 0.374 & 7.799 & 4.274 & 3.899 & 4.685 & 0.692 & 4.672 & -4.274 \\ \text { SD8 } & -8.145 & -0.045 & 8.145 & 0.045 & 8.100 & 4.095 & 4.050 & 4.141 & 0.529 & 4.590 & -4.095 \\ \text { SD9 } & -7.885 & 0.0451 & 7.885 & 0.045 & 7.931 & 3.920 & 3.965 & 3.875 & 0.473 & 4.427 & -3.920 \\ \text { SD10 } & -7.879 & 0.0511 & 7.879 & 0.051 & 7.930 & 3.914 & 3.965 & 3.863 & 0.470 & 4.422 & -3.914\end{array}$

\subsection{Kinetics and Thermodynamic Parameters}

The thermodynamic properties of the reactions were followed to determine the spontaneity of the process using theoretical calculations and the energy (barrier) requirement with respect to the formation of the transition states. According to Agwupuye et al [33], the enthalpy of reaction is the energy difference between the products and the reactants. Mathematically, it is the sum of the internal energy (q) plus the pressure (p) and the volume (v) of a chemical system. Exothermic reactions give out heat to the surrounding and are described as being spontaneous $(\Delta \mathrm{H}<0)$ while 
endothermic reactions absorb heat from the surroundings $(\Delta \mathrm{H}>0)$ hence, non-spontaneous. All the calculations for enthalpy and free energy of the reactions were done using the data obtained from the optimized structures adopting the following equations according to [33].

$\Delta \mathrm{H}^{*}(298 \mathrm{~K})=\sum_{\text {product }} \Delta \mathrm{H}_{\mathrm{f}}^{*}$ prod. $(298 \mathrm{~K})-\sum_{\text {reactant }} \Delta \mathrm{H}^{*}$ react $(298 \mathrm{~K})$

$\Delta \mathrm{H}_{\mathrm{f}}^{*}(298 \mathrm{~K})=\sum(\varepsilon \mathrm{o}+\varepsilon \mathrm{Hcorr})$ products $-\sum(\varepsilon \mathrm{o}+\varepsilon$ Hcorr $)$ reactants

$\Delta \mathrm{G}^{*}(298 \mathrm{~K})=\sum(\varepsilon 0+\varepsilon \mathrm{Gcorr})$ products $-\sum(\varepsilon 0+\varepsilon \mathrm{Gcorr})$ reactants

$\varepsilon_{o}$ is the electronic energy while $\mathrm{H}_{\text {corr }}$ is the total energy and thermal correction to H. The Gibb's free energy of activation $G^{*}$ calculated using equation (9) in this study showed negative values for all the reaction systems except for SD8-dienophile system which has a positive value $(0.58$ $\mathrm{Kcal} / \mathrm{mol}$ ) that indicates unspontaneous process. These negative values obtained for both enthalpy and free energy of the reaction (Table 2) indicates that the process were exothermic and agrees with previous reports that Diels-Alder reactions of 1, 3-butadienes involves the evolution of heat and hence, spontaneous $[34,35]$.

Table 2: Kinetics and Thermodynamic Parameters for the different reactants (A), transition states $\left(\mathrm{AB}^{*}\right)$, and products $(\mathrm{AB})$

\begin{tabular}{|c|c|c|c|c|c|c|c|c|}
\hline & & A & B & $\mathrm{AB}^{*}$ & $\mathrm{AB}$ & $\begin{array}{c}\Delta \mathrm{H} \text { or } \\
\Delta \mathrm{G}\end{array}$ & $\Delta \mathrm{G}^{*}$ & K \\
\hline & E0 + Ehorr & -2766.3 & 94.5426 & 2860.81 & -2860.9 & 1795228 & & \\
\hline & & - & 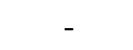 & - & - & 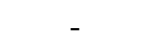 & & \\
\hline \multirow[t]{2}{*}{ SD1 } & E0 + Egorr & $\begin{array}{c}2766.34 \\
-\end{array}$ & $\begin{array}{c}94.5683 \\
-\end{array}$ & $\begin{array}{c}2860.86 \\
-\end{array}$ & $\begin{array}{c}2860.95 \\
-\end{array}$ & 1795241 & -0.01854 & 2.514636271 \\
\hline & E0 + Ehorr & $\begin{array}{c}654.667 \\
-\end{array}$ & $\begin{array}{c}94.5426 \\
-\end{array}$ & $\begin{array}{c}749.183 \\
-\end{array}$ & $\begin{array}{c}749.271 \\
-\end{array}$ & -470158 & 2111.723 & \\
\hline \multirow[t]{2}{*}{$\mathrm{SD} 2$} & E0 + Egorr & $\begin{array}{c}654.706 \\
-\end{array}$ & $\begin{array}{c}94.5683 \\
-\end{array}$ & $\begin{array}{c}749.226 \\
-\end{array}$ & $\begin{array}{c}749.313 \\
-\end{array}$ & -470171 & -0.01654 & 2.275462433 \\
\hline & E0 + Ehorr & $\begin{array}{c}350.946 \\
-\end{array}$ & $\begin{array}{c}94.5426 \\
-\end{array}$ & $\begin{array}{c}445.461 \\
-\end{array}$ & $\begin{array}{c}445.551 \\
-\end{array}$ & -279570 & 303.8133 & \\
\hline \multirow[t]{2}{*}{ SD3 } & E0 + Egorr & $\begin{array}{c}350.992 \\
-\end{array}$ & $\begin{array}{c}94.5683 \\
-\end{array}$ & $\begin{array}{c}445.512 \\
-\end{array}$ & $\begin{array}{c}445.599 \\
-\end{array}$ & -279587 & -0.02287 & 3.118439902 \\
\hline & E0 + Ehorr & $\begin{array}{c}311.682 \\
-\end{array}$ & $\begin{array}{c}94.5426 \\
-\end{array}$ & $\begin{array}{c}406.197 \\
-\end{array}$ & $\begin{array}{c}406.286 \\
-\end{array}$ & -254931 & 39.36265 & \\
\hline \multirow[t]{2}{*}{ SD4 } & E0 + Egorr & $\begin{array}{c}311.725 \\
-\end{array}$ & $\begin{array}{c}94.5683 \\
-\end{array}$ & $\begin{array}{c}406.246 \\
-\end{array}$ & 406.332 & -254947 & -0.02184 & 2.962600977 \\
\hline & E0 + Ehorr & $\begin{array}{c}294.306 \\
-\end{array}$ & $\begin{array}{c}94.5426 \\
-\end{array}$ & $\begin{array}{c}388.823 \\
-\end{array}$ & -388.91 & -244029 & 17.47012 & \\
\hline \multirow[t]{2}{*}{ SD5 } & E0 + Egorr & $\begin{array}{c}294.344 \\
-\end{array}$ & $\begin{array}{c}94.5683 \\
-\end{array}$ & $\begin{array}{c}388.866 \\
-\end{array}$ & $\begin{array}{c}-388.95 \\
-\end{array}$ & -244041 & -0.01756 & 2.393846751 \\
\hline & E0 + Ehorr & $\begin{array}{c}423.792 \\
-\end{array}$ & $\begin{array}{c}94.5426 \\
-\end{array}$ & $\begin{array}{c}518.308 \\
-\end{array}$ & $\begin{array}{c}518.396 \\
-\end{array}$ & -325281 & -29.396 & \\
\hline \multirow[t]{2}{*}{ SD6 } & E0 + Egorr & $\begin{array}{c}423.838 \\
-\end{array}$ & $\begin{array}{c}94.5683 \\
-\end{array}$ & $\begin{array}{c}518.539 \\
-\end{array}$ & $\begin{array}{c}518.444 \\
-\end{array}$ & -325412 & -0.20448 & 2.904097312 \\
\hline & E0 + Ehorr & $\begin{array}{c}308.359 \\
-\end{array}$ & $\begin{array}{c}94.5426 \\
-\end{array}$ & $\begin{array}{c}402.878 \\
-\end{array}$ & $\begin{array}{c}402.963 \\
-\end{array}$ & -252848 & 115.5287 & \\
\hline SD7 & E0 + Egorr & 308.401 & 94.5683 & 402.924 & 402.007 & -252235 & -0.02194 & 2.97692474 \\
\hline
\end{tabular}




\begin{tabular}{|c|c|c|c|c|c|c|c|c|}
\hline & & - & - & & - & & & \\
\hline & E0 + Ehorr & $\begin{array}{c}347.638 \\
-\end{array}$ & $\begin{array}{c}94.5426 \\
-\end{array}$ & $\begin{array}{c}-441.54 \\
-\end{array}$ & $\begin{array}{c}442.243 \\
-\end{array}$ & -277110 & -38.5709 & \\
\hline \multirow[t]{2}{*}{ SD8 } & E0 + Egorr & $\begin{array}{c}347.685 \\
-\end{array}$ & $\begin{array}{c}94.5683 \\
-\end{array}$ & $\begin{array}{c}441.593 \\
-\end{array}$ & $\begin{array}{c}442.291 \\
-\end{array}$ & -277127 & 0.58753 & $2.05314 \mathrm{E}-13$ \\
\hline & E0 + Ehorr & $\begin{array}{c}309.531 \\
-\end{array}$ & $\begin{array}{c}94.5426 \\
-\end{array}$ & $\begin{array}{c}404.046 \\
-\end{array}$ & $\begin{array}{c}404.134 \\
-\end{array}$ & -253581 & 38.20722 & \\
\hline \multirow[t]{2}{*}{ SD9 } & E0 + Egorr & $\begin{array}{c}309.573 \\
-\end{array}$ & $\begin{array}{c}94.5683 \\
-\end{array}$ & $\begin{array}{c}404.093 \\
-\end{array}$ & $\begin{array}{c}404.179 \\
-\end{array}$ & -253596 & -0.01977 & 2.67270099 \\
\hline & E0 + Ehorr & $\begin{array}{c}270.277 \\
-\end{array}$ & $\begin{array}{c}94.5426 \\
-\end{array}$ & $\begin{array}{c}364.793 \\
-\end{array}$ & $\begin{array}{c}364.882 \\
-\end{array}$ & -228950 & 39.34812 & \\
\hline SD10 & E0 + Egorr & 270.316 & 94.5683 & 364.836 & 364.923 & -228962 & -0.0166 & 2.283169293 \\
\hline
\end{tabular}

\subsection{Electron Localization Function (ELF) Analysis}

Domingo [36] insisted that electron density is responsible for the chemical reactivity of molecules instead of molecular orbital relationships. He used the well accepted DFT and topological analysis to establish his facts. However, in this study we employed his approach of Molecular Electron Density Theory (MEDT) and Global Electron Density Transfer (GEDT) to ascertain the reactivity of substituted 1, 3-butadienes. In our study, nitrogen to carbon bonding disynaptic basins of the halogen-substituted, cycloalkane-substituted and carbonyl substituted dienes were observed to be in agreement with Lewis representation of covalent bonding [37] and presented in Table 3. For all the compounds studied, the atomic contribution of the selected basin is roughly equal due to their close range of electron affinity values. From Table 3, the halogen and hydroxyl substituted dienes exhibited ionic character for the N-C bond with SD1 having the least ionic character reflected in its high basin volume and low population basin values. This ionic character is manifest in the lesser volume and population basin volume due to the pull of electrons by the electron withdrawing substituents.

In contrast, the cycloalkane and carbonyl substituted dienes displayed a bonding character of the $\mathrm{N}-\mathrm{C}$ bond tilted more towards the covalent side. The electron donating behaviour of the substituents in this case provides for a concentration of electrons more at the bonding site (N-C) causing an increase in the possibility for a double bond at the bonding site. The high volume and low population basin of SD6 suggest possible complete covalent character while the other cycloalkanes show dual characteristics of a double and single bond between N-C at their transition state. However, with the second highest volume and highest population, SD7 has a defined double bond relationship between nitrogen and carbon. 


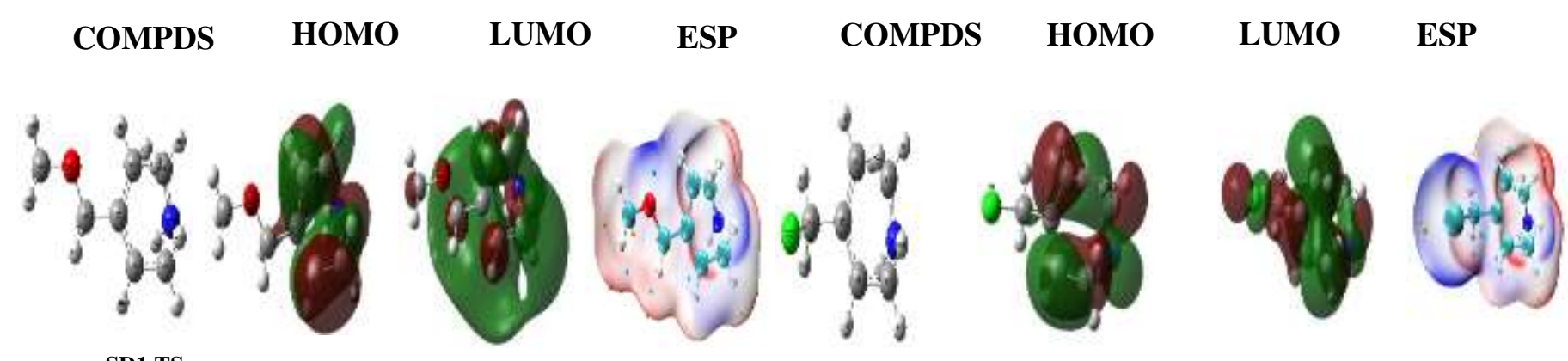

SD2 TS

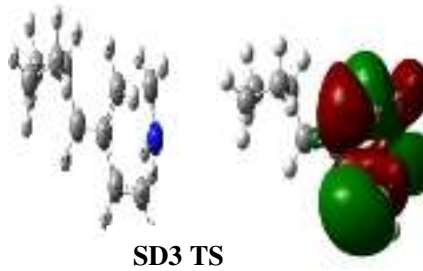

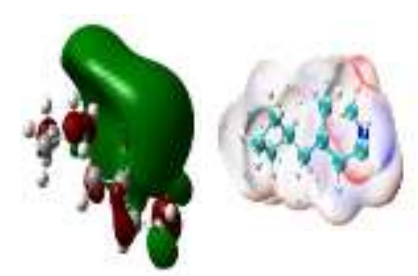

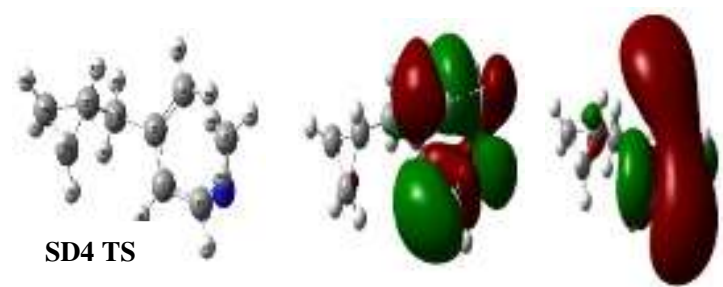

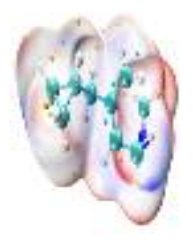

$\int_{0}^{20}$
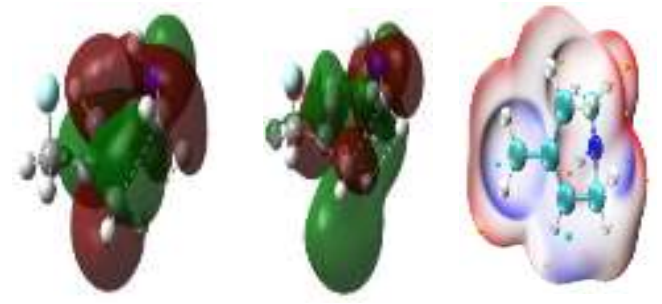

"arising
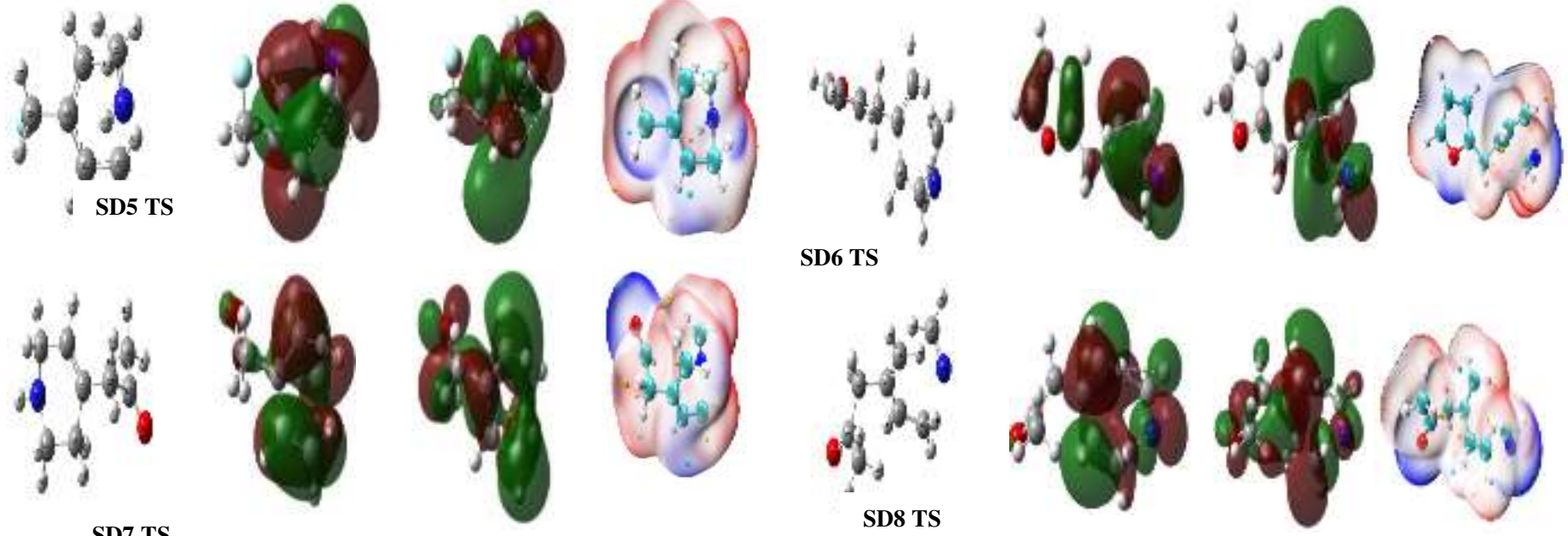

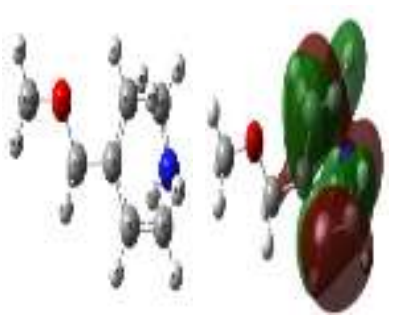

SD9 TS
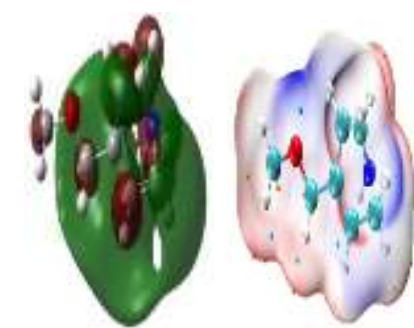

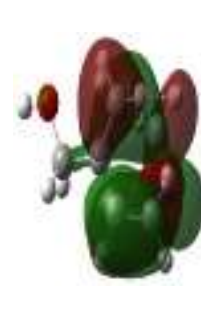

SD10

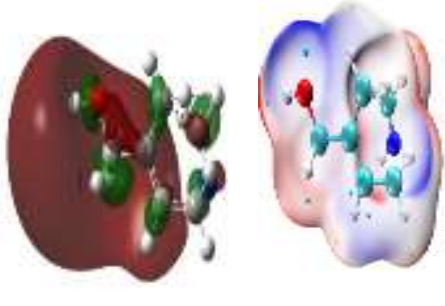

TS

Fig. 
Table 3: Volume and population basin of SD1-SD10 substituted dienes

\begin{tabular}{|c|c|c|}
\hline V(N, C) & Volume basin & Population basin (e) \\
\hline SD1 & 279.2150 & 0.0094 \\
\hline SD2 & 153.0830 & 0.0065 \\
\hline SD3 & 143.0830 & 0.0178 \\
\hline SD4 & 135.9140 & 0.0144 \\
\hline SD5 & 189.0190 & 0.0251 \\
\hline SD6 & 172.2280 & 0.0007 \\
\hline SD7 & 217.0260 & 0.0369 \\
\hline SD8 & 191.1260 & 0.0077 \\
\hline SD9 & 145.0420 & 0.0189 \\
\hline SD10 & 144.2970 & 0.0187 \\
\hline
\end{tabular}

\section{Conclusion}

The study showed that synthesis of hetero-nuclear aza-cyclohexene is achieved faster with furan substituent of energy gap $7.534 \mathrm{eV}$ and molecular hardness of 3.677 compared to 7.799 (SD7) $8.100 \mathrm{eV}$ (SD8) and 3.899 (SD7) - 4.050 (SD8) respectively scored by other substituents noting that smaller energy gap leads to higher reactivity. Other parameters; QTAIM, NBO, HOMOLUMO, including descriptors and Thermodynamics showed that first furan had the highest positive influence on the reactivity of 1, 3-butadiene with imine dienophile followed by other bulky groups; cycloalkanes, carbonyls and less by hydroxyl group and the halogens. It was observed that $\mathrm{HCOCH}_{3}$ (SD8) retarded the rate of the reaction following the calculated Gibb's free energy of activation. Again, the high volume and low population basin of SD6 in the ELF analysis suggest possible complete covalent character while the other cycloalkanes show dual characteristics of a double and single bond between N-C at their transition states. 


\section{Acknowledgement}

This research was not funded by any agency; however, the authors are thankful to all the members of the Computational and Bio-Simulation research group, Department of Pure and Applied Chemistry, University of Calabar, Nigeria.

Funding: No external funding was received.

Conflict of interest: All authors unanimously declared zero conflict of interest.

Availability of Data and Material: All Data and Materials are available within the Manuscript and the Supporting Information.

\section{Code Availabilty: N/A}

\section{Author's contribution}

The research project was conceptualized, designed, and supervised by Hitler Louis. Theoretical calculations and all results analysis along with manuscript draft was conducted by Fredrick Asogwa. Obieze C. Enudi performed theoretical calculations while Dollars I. Kenthurky performed the results analysis and paper writing.

\section{References}


[1] Song Yu, Hans M de Bruijn, Dennis Svatunek, Trevor A. Hamlin, and Matthias F. Bickelhaut (2018) Factors Controling the Diels-Alder Reactivity of Hetero-1, 3-butadienes. Chem. Op. Wiley Online Library Pp 1-11 DOI:10.1002/open.201800193

[2] Nicolaou, K.C., Synder, S.A., Montagnon, T., Vassilikogiannakis, G. (2002). The DielsAlder Reaction in Total Synthesis. Angew Chem. Int. Ed.Eng 114:1742-1773

[3] Tasdelen M. A. (2011). Diels-Alder "Click" Reactions: Recent Application in Polymer and Material Science. Polym. Chem. 2: 2133-2145

[4] Yang, J., Liang, Y., Seckutee, J., Devaraj K.N. (2014). Synthesis and Reactivity of 1-methyl3-substituted Cyclopropene Mini-tags for Tetrazine Bioorthogonal Reactions. Chem. A Eur. J 20(12): 3365-3375

[5] Cole, C.M., Yang, J., Seckute, J., Devaraj K.N. (2013). Fluorescent Live-Cell Imaging of Metabolically incorporated unnatural Cyclopropene-mannosamine Derivatives. ChemBiochem $14: 205-208$

[6] Rossin R., Van Duinhoven, S.M.J., Ten Hoere, W., Jansen H.M., Kleijn, L.H.J., Hoeben, F.J.M., Versteegen R.M., Robillard M. S. (2016). Triggered Drug Release from Antibody Drug Conjugate Using fast "Clickto release" Chemistry in Mice. Bioconjugate Chem. 27:1697-1706

[7] Boger, D.L., Cassidy, K.C., Nakahara, J (1993). Streptonigrone. J. Am. Chem. Soc. 115:10733-10741

[8] Han, G, Laporte, M.G., Folmer, J.J., Werner, K.M., Weinreb, S.M. (2000). Total Synthesis of the Securinegaalkaloids (+)-14, 15-Dihydronorsecurinine, (-)- Norsecurinine, and Phyllanthine. J. Org. Chem.65:6293-6306

[9] Rajapaksa, N.S., McGowan, M.A., Rienzo, M., Jacobsen, E.N. (2013). Enantioselective Total Synthesis of (+)- reserpine. Org. Lett.15:706-709

[10] Bounora, P., Olsen, J., Oh, T (2001). Recent Developments in Imino Diels-Alder Reactions. Tetra. R. 575(57):6099-6138

[11] Boger, D.; Weinreb, S. M. (1987). Hetero Diels-Alder Methodology in Organic Synthesis. Academic:San Diego, Chapter 2, 34-70; Chapter 9, pp 239-299.

[12] Asadi, M., Asadi, Z., Torabi, S., \& Lotfi, N. (2012). Synthesis, characterization and thermodynamics of complex formation of some new Schiff base ligands with some transition metal ions and the adduct formation of zinc Schiff base complexes with some organotin chlorides. Spectrochimica Acta Part A: Molecular and Biomolecular Spectroscopy, 94, 372-377. http://dx.doi.org/10.1016/j.saa.2012.03.061

[13] Chen, L., Xiang, Y., \& Feng, T. (2012). Hybrid compounds of Schiff base Cu, Fe, Co complexes with molybdovanadophoric heteropolyacids: Synthesis, characterization and their catalytic performance to hydroxylation of benzene with $\mathrm{H}_{2} \mathrm{O}_{2}$. Applied Organometallic Chemistry, 26, 108-113. http://dx.doi.org/10.1002/aoc.v26.326. 
[14] Coulthard, G., Unsworth, W, P., \& Taylor, R. J. K. (2015). Propylphosphonic anhydride (T3P) mediated synthesis of $\beta$-lactams from imines and aryl-substituted acetic acids. Tetra. Lett., $56,3113-3116$.

[15] Dogan, F., \& Kaya, I. J. (2013). Thermal decomposition studies of Schiff-base-substitute polyphenol-metal complexes. J. App Polym Sci., 128, 3354-3362.

[16] Doi, T., Kawai, H., Murayama, K., Kashida, H., \& Asauna, H. (2016). Synthesis and pharmacologicalporperties of 2-azabicyclo [2.2.2] octane derivatives representing conformational restricted isopethidine analogues. Eur. J. of Med. Chem., 22, 1-7.

[17] Ganguly, A., Chakraborty, P., Banerjee, K., \& Choudhuri, S. K. (2014). The role of a Schiff base scaffold, N-(2-hydroxy acetophenone) glycinate-in overcoming multidrug resistance in cancer. Eur. J. Pharm. Sci., 51, 96-104.

[18] Jhaumeer-Laulloo, S., Gupta Bhowon, M. G., Mungur, S., Fawzi Mahomoodally, M. F., \& Hussein Subratty, A. H. (2012). In vitro anti-glycation and anti-oxidant properties of synthesized schiff bases. Med. Chem., 8, 409-414. http://dx.doi.org/10.2174/157340641120803040933.

[19] Kielland, N., Escudero-Adán, E. C., Martínez Belmonte, M. M., \& Kleij, A. W. (2013). Unsymmetrical octanuclear Schiff base clusters: Synthesis, characterization and catalysis. Dalt. Trans., 42, 1427-1436. http://dx.doi.org/10.1039/C2DT31723K

[20] Lee, S. K., Tan, K. W., Ng, S. W., Ooi, K. K., Ang, K. P., Abdah, M. A. (2014). Zinc (II) complex with a cationic Schiff base ligand: Synthesis, characterization, and biological studies. Spectrochimica Acta Part A: Molecular and Biomolecular Spectroscopy, 121, 101-108. http://dx.doi.org/10.1016/j.saa.2013.10.084

[21] Qin, W., Long, S., Panunzio, M., \& Biondi, S. (2013). Schiff bases: A short survey on an evergreen chemistry tool. $\quad$ Mole., $18, \quad 12264-12289$. http://dx.doi.org/10.3390/molecules181012264

[22] Seifzdeh, D., Basharnavaz, H., \& Bezaatpour, A. (2014). A Schiff base compound as effective corrosion inhibitor for magnesium in acidic media. Mat. Chem. and Phy., 138, 794802.

[23] Zarei, M. (2014). An efficient and green method for the synthesis of 2-azetidinones mediated by propylphosphonic anhydride (T3P®). Monatshefte für Chemie-Chemical Monthly, $145,1495-1499$.

[24] Friguelli F. andTaticchi A. (2002). In The Diels-Alder Reaction (England: John Wiley)

[25] Safa Ali, A., Jafar, I, N., and Samira Z. (2017). Regioselectivity in the Hetero-Diels-Alder reactions of styrenes with 2-aza-1,3-butadiene: a DFT study. J. Chem. Sci. Vol. 129, No. 8, pp. 1319-1325. DOI 10.1007/s12039-017-1332-0

[26] Yu, Y., Xin, L., and Kuling, D. (2002). Acid-Free Aza Diels-Alder Reaction of Danishefsky's Diene with Imines, Org. Lett. vol.4 No. 19:3309-3311. 
[27] Frisch J.M., Trucks, G. W., Schlegel, H. B., Scuseria, G. E., Robb, M. A., Cheeseman, J.R., Scalmani G et al (2016). Gaussian 16, Gaussian. Inc., Walliford CT.

[28] Lu, T., Chen, F. (2012). Multiwfn: a functional wavefunction analyzer, J. Cumput. Chem. $33: 580-592$

[29] Eric Glendening, D., Clark, L. R., Frank, W. (2013). NBO 6.0: Natural bond order analysis program, J. Comput. Chem. 34(16): 1429-1437.

[30] Zhao, Y., Donald, T. G. (2008). The Mo6 suite of density functionals for main group thermochemistry, thermochemical kinetics noncovalent interactions, excited states and transition elements: two new functionals and systematic testing of four Mo6-class functionals and 12 other functionals, Theor. Chem. Acc. 120(1-3): 215-241.

[32] Arumugam, A., Madhu, D. K., Madhavan J., and Venkatachalam T. (2019). Theoritical Investigationof Steric Effect Influence on Reactivity of Substituted Butadienes with Bromocyclobutenone, J. Chem. Inf. Model 59:2231-2241.

[33] Agwupuye J.A., Hitler, L., Unimuke, T.O., David, P., Ubana, E. I., Yusuff, L. M. (2021). Electronic structure investigation of the stability, reactivity, NBO analysis, thermodynamics and the nature of the interactions in methyl-substituted imidazolium-based ionic liquids, J. Mol Liq.

[34] Morrison, R.T. and Boyd, R.N. (2002). Organic Chemistry, $6^{\text {th }}$ Ed. Prentice-Hall, India.

[35] Anslyn Eric, V. and Dougherty D.A. (2006). Modern Physical Organic Chemistry, J. Chem. Educ. 83(3): 387.

[36] Domingo, L.R. (2016). Molecular Electron Density Theory: A Modern View of Reactivity in Organic Chemistry, Mole. 21 Pp 1319.

[37] Grzegorz, M., Agnieszka J. Gordon \& Slawomir B. (2020). The nature of multiple boronnitrogen bonds studied using electron localization function (ELF), electron density (AIM) and natural bond orbital (NBO) methods. J. Mole. Model. 26, 136. 


\section{Supplementary Files}

This is a list of supplementary files associated with this preprint. Click to download.

- FredsSI.docx 